\title{
Enzyme Studies in a Patient with Saccharopinuria: A Defect of Lysine Metabolism
}

\author{
Florence G. I. Fellows and Nina A. J. Garson ${ }^{[39]}$ \\ Department of Child Health, The Queen's University of Belfast, Belfast, Northern Ireland \\ Extract
}

Elevated levels of saccharopine, lysine, and citrulline in urine and plasma were observed in a patient suffering from saccharopinuria. Using radioisotope methods the lysine-degradative enzymes, lysine-oxoglutarate reductase and saccharopine dehyrogenase, were studied in skin fibroblasts grown from this patient and from healthy subjects.

The results show that, in contrast to healthy individuals (range 177-320 pmol formed $/ \mathrm{min} / \mathrm{mg}$ protein), the paitent's fibroblasts are completely lacking in saccharopine dehydrogenase activity, which accounts for the presence of the high levels of saccharopine. The patient also has a reduced level of lysine-oxoglutarate reductase activity (333 pmol saccharopine formed $/ \mathrm{min} / \mathrm{mg}$ protein; range $550-1,570 \mathrm{nmol}$ ), which may in part explain the hyperlysinemia. A further enzyme saccharopine oxidoreductase which metabolizes saccharopine to lysine was found to be present in the patient's fibroblasts (63 pmol lysine formed $/ \mathrm{min} / \mathrm{mg}$ protein) but absent from those of healthy control subjects. This indicated induction of this enzyme by the patient in an attempt to reduce the high levels of saccharopine in her tissues and body fluid.

\section{Speculation}

There are two interesting features of this patient with saccharopinuria which the present studies have not clearly defined, namely the presence of high levels of lysine and citrulline found in plasma and urine.

There are three possible explanations for the hyperlysinemia which may be operating singly or in combination. Depression in activity of lysine-oxoglutarate reductase (the patient possesses $37 \%$ of the normal activity). Inhibitory effect of saccharopine on lysine-oxoglutarate reductase (in vitro studies). Induction by the patient of saccharopine oxidoreductase which metabolizes saccharopine to lysine.

No explanation has yet been found for the high levels of citrulline in plasma and urine.

\section{Introduction}

The initial degradative steps of lysine metabolism in mammals involves two distinct routes, an oxidative deamination of the $\alpha$-amino group and a transamination of the $\epsilon$-amino group.

In 1954 [21] it was demonstrated in vivo that a significant amount of L-pipecolic acid was formed when DL- $\left(\epsilon^{-15} \mathrm{~N}\right)$ lysine was administered to rats, and it was concluded that L-lysine was converted to pipecolic acid after removal of its $\alpha$-amino group. However, other work has shown that L-pipecolic acid is principally a product of $\mathrm{D}-\mathrm{lysine}$ [13], and therefore unlikely to be an intermediate in the major pathway of lysine degradation in mammals. Gatfield et al. [11] in 1968 reported a patient with hyperpipecolatemia who, at 18 months, presented clinically with a degenerative neurologic disease and hepatomegaly. The patient had raised levels of pipecolic acid in blood and urine; no increase in 
lysine in plasma was noted. From oral load studies it was revealed that the metabolism of pipecolic acid was impaired but that of lysine was normal. This was interpreted as support for the concept that in humans the pipecolic acid pathway is a minor route for lysine catabolism. This fact was also supported by other work [29] in which normal children and patients with familial hyperlysinemia were given $\mathrm{L}-\left(\mathbf{U}^{-14} \mathrm{C}\right)$ lysine by intramuscular injection and labeled pipecolic acid was found in the urine, which indicated its derivation from lysine.

The alternative pathway for lysine degradation is via saccharopine involving the removal of the $\epsilon$-amino group in the initial steps. Saccharopine was first identified and isolated from yeast in 1961 [6] and has been shown to be the precursor of lysine biosynthesis in yeast $[18,19]$. It has been demonstrated that saccharopine is formed by L-lysine in the presence of $\alpha$-oxoglutarate by isolated rat liver mitochondria [15] and an enzyme, lysine-oxoglutarate reductase which catalyzes the formation of saccharopine from lysine with $\alpha$-oxoglutarate has been partially purified from human liver [16]. Several patients with hyperlysinemia have been described in the literature $[1,12,28]$ and in three of these patients it has been shown [5] that the hyperlysinemia results from a deficiency of lysine-oxoglutarate reductase.

Saccharopine is not normally present in human plasma and urine and its presence in human physiologic fluids (plasma, cerebrospinal fluid, and urine) was first reported by Carson et al. in 1968 [4] in a 22-yearold woman. In addition to large quantities of saccharopine in the urine, excess amounts of lysine and citrulline were found. Homocitrulline, homoarginine, and $\epsilon-N$-acetyl lysine were also observed. A second patient with saccharopinuria was reported from Finland in 1972 [24]. This patient excreted large amounts of lysine and saccharopine but, unlike the first patient, clid not show an abnormality of citrulline metabolism. A deficiency of the saccharopine degrading enzyme was found in the Finnish patient [23]. The present paper reports the study of the enzymes involved in saccharopine metabolism in the original patient with saccharopinuria [4] and in healthy control subjects utilizing skin fibroblast cultures and radioisotope techniques.

\section{Materials and Methods}

$\alpha-\left({ }^{14} \mathrm{C}_{5}\right)$ Oxoglutarate and $\mathrm{L}-\left(\mathrm{U}^{-14} \mathrm{C}\right)$ lysine- $\mathrm{HCl}$ were obtained from the Radiochemical Centre [30]. L-Saccharopine was purified from the urine of the patient with saccharopinuria [8].
Preparation of ${ }_{L-}\left({ }^{14} C_{G I u}\right)$ Saccharopine and ${ }_{L-}\left(U_{-14} C_{L y s}\right)-$ Saccharopine

$\mathrm{L}-\left({ }^{14} \mathrm{C}_{\mathrm{Glu}}\right)$ Saccharopine $\left(\epsilon-N-\left({ }^{14} \mathrm{C}_{5}\right)\right.$ glutaryl-L-lysine $)$ was synthesized enzymatically with a partially purified lysine-oxoglutarate reductase preparation from ox liver [16]. The incubation medium contained L-lysine-HCl (4 $\mu \mathrm{mol}), \alpha-\left({ }^{14} \mathrm{C}_{5}\right)$ oxoglutarate $(50 \mu \mathrm{Ci}), \alpha$-oxoglutarate (2 $\mu \mathrm{mol})$, NADPH $(4 \mu \mathrm{mol})$, potassium phosphate buffer, pH $7.0(50 \mu \mathrm{mol})$, enzyme extract (1 mg protein) and water to a final volume of $1 \mathrm{ml}$. The incubation was for 90 min and under a constant flow of nitrogen gas. The reaction was terminated by the addition of sulfosalicylic acid $(50 \mathrm{mg})$ which precipitated the protein. $\mathrm{L}-\left({ }^{14} \mathrm{C}_{\mathrm{Glu}}\right)$ Saccharopine in the supernatant was separated by the use of a Technicon amino acid autoanalyzer [26, 31] and the appropriate fraction was collected by a BTL fraction collector [32]. This fraction was passed through a Dowex 50W-X 8 column ( 1 by 5 $\mathrm{cm})$. The column was first washed with deionized water $(500 \mathrm{ml})$ and then eluted with $2 \mathrm{M} \mathrm{NH}_{4} \mathrm{OH}$. The eluate was dried and redissolved in water. The product, $\mathrm{L}-\left({ }^{1+} \mathrm{C}_{\mathrm{Glu}}\right)$ saccharopine, was shown to behave homogeneously by both high voltage electrophoresis and two dimensional chromatographic analysis. The total yield was $30 \mu \mathrm{Ci}$.

$\mathrm{L}$-(U-14 $\left.\mathrm{C}_{\mathrm{L}, \mathrm{ys}}\right)$ Saccharopine $\left(\epsilon-N\right.$-(glutaryl-2)-L- $\left(\mathrm{U}-{ }^{14} \mathrm{C}\right)$ lysine) was prepared by incubation of $\mathrm{L}-\left(\mathrm{U}^{14} \mathrm{C}\right)$ lysine and $\alpha$-oxoglutarate with the lysine-oxoglutarate reductase preparation using the same method as for the preparation of $\mathrm{L}-\left({ }^{14} \mathrm{C}_{\mathrm{Glu}}\right)$ saccharopine.

\section{Desalting Technique}

Cation exchange column chromatography was used for desalting the incubation media and amino acid fractions. Dowex 50W-X8 resin, 200-400 mesh $(\mathrm{H}+$ form) was packed into the column $(1$ by $5 \mathrm{~cm})$. The sample ( $\mathrm{pH} 2.0)$ was loaded onto the resin and the column was washed with deionized water $(50 \mathrm{ml})$ then eluted with $2 \mathrm{M} \mathrm{NH}_{4} \mathrm{OH}(20 \mathrm{ml})$. The first 4 -ml eluate was discarded and the following $10 \mathrm{ml}$ was collected. After drying the residue was redissolved in water. This latter aqueous amino acid mixture was subsequently analyzed by either two dimensional chromatography or high voltage electrophoresis.

\section{High Voltage Electrophoresis}

A Shandon high voltage electrophoresis apparatus, model L24 [33], was used for all separations. All samples were desalted before the application of electrophoresis. Whatman no. 3MM paper was used. Electro- 
phoresis was conducted at $3,000 \mathrm{~V}$ for $90 \mathrm{~min}$ in sodium barbital buffer $(0.05 \mathrm{~m}$, pH 8.2). Under these conditions lysine and other basic amino acids traveled to the cathode, and saccharopine, glutamate, and other acidic amino acids to the anode. After complete drying the separated amino acid spots were located by ninhydrin $(0.1 \%$ in acetone, $w / v)$.

\section{Two Dimensional Paper Chromatography}

After prior desalting, samples were applied to squares of Whatman no. 1 chromatography paper and chromatographed in butan-l-ol-pyridine-water $(1 / 1 / 1$, $\mathrm{v} / \mathrm{v}$ ) followed by ammoniated phenol-water $(2 / 1, \mathrm{w} / \mathrm{v})$ and the amino acids were visualized by ninhydrin in acetone [25].

\section{Cell Cultures}

Pinch biopsies of skin [7] were taken and the fibroblasts were grown in tissue culture medium (minimum essential medium [34]) supplemented with $10 \%$ fetal bovine serum and antibiotics at $35^{\circ}$. The cells were first grown in medical flats and finally roller cultured in Winchester bottles (80 oz). The fibroblasts used in the enzyme studies were harvested between passages 8 and 12 .

\section{Isolation of Fibroblast Mitochondria}

All procedures were carried out at temperatures $0-4^{\circ}$.

Fibroblasts from four Winchester bottles with confluent sheets of cells (approximately $40 \mathrm{mg}$ protein total) were harvested. The cells were washed twice with a buffered isotonic sucrose solution (sucrose $(0.25$ M); Tris-HCl, pH 7.4 (5 mM); EDTA (1 mM)) and separated by centrifugation. They were resuspended in the buffered sucrose solution $(4 \mathrm{ml})$ and were then homogenized for $2 \mathrm{~min}$ in a $10-\mathrm{ml}$ Potter-Elvehjem MSE homogenizer [35] with a Teflon pestle. The homogenization was interrupted at 20 -s intervals and the suspension was rechilled to prevent any appreciable temperature rise. The homogenate was diluted to $8 \mathrm{ml}$ with the buffered sucrose solution and centrifuged at $700 \times g$ for 10 min in 10-ml tubes fixed in an ( 8 by $50 \mathrm{ml}$ ) fixed angle rotor of an MSE high speed 18 centrifuge [35]. The supernatant was decanted into a clean precooled tube and centrifuged at $9,000 \times g$ for $7 \mathrm{~min}$. This second supernatant was discarded and the mitochondrial pellets were twice resuspended (by progressive dilution with the buffered sucrose solution to a final volume of $8 \mathrm{ml}$ ) and recentrifuged at $9,000 \times g$ for $7 \mathrm{~min}$. Finally, the pellets were resuspended in $0.25 \mathrm{ml}$ of a standard buffer solution (potassium phosphate, $\mathrm{pH} 7.0(0.1 \mathrm{M})$; $\mathrm{KCl}(0.15 \mathrm{M})$; EDTA (1 mM)). The yield of mitochondrial protein was approximately $5 \%$ of that in the original whole cell homogenate.

\section{Protein Estimation}

Protein was measured by reference to a calibration curve prepared from bovine serum albumin (20). Enzyme Assays

Whole cell homogenate. Fibroblasts were harvested, washed twice, and resuspended in the standard buffer solution. The cell suspension was sonicated $3 \times 20 \mathrm{~s}$ in an ultrasonic disintegrator (100 W [35]) and the sonicate was tested for enzyme activities.

Mitochondrial enzyme preparation. The mitochondria suspension was sonicated for $3 \times 20 \mathrm{~s}$ and the mitochondria sonicate tested for enzyme activities.

Lysine-oxoglutarate reductase. The assay conditions were modified from those as previously described [16]. The incubation medium contained, in $0.1 \mathrm{ml}$ : L-lysineHCl $(0.25 \mu \mathrm{mol})$; L-(U-14C)lysine- $\mathrm{HCl}(0.1 \mu \mathrm{Ci}) ; \alpha$-oxoglutarate $(0.5 \mu \mathrm{mol})$; NADPH $(0.5 \mu \mathrm{mol})$; potassium phosphate buffer, pH $7.0(20.0 \mu \mathrm{mol})$, and enzyme. preparation (150 $\mathrm{g}$ protein). Incubation was for 30 min at $30^{\circ}$ and under a constant flow of nitrogen gas. The reaction was terminated by the addition of sulfosalicylic acid $(25 \mathrm{mg})$ and the precipitated protein was removed by centrifugation. L-Saccharopine $(1.0 \mu \mathrm{mol})$ was added into the supernatant as a carrier. The medium was desalted by a Dowex 50W-X 8 column. The desalted aqueous amino acid mixture was then subjected to high voltage electrophoresis to separate $\left(\mathrm{U}^{14} \mathrm{C}_{\mathrm{L}, \mathrm{ys}}\right)$ saccharopine from $\left(\mathrm{U}^{-14} \mathrm{C}\right)$ lysine. The radioactivity was determined by liquid scintillation.

Saccharopine dehydrogenase. The assay conditions were modified from those previously described [17]. The incubation medium contained, in $0.1 \mathrm{ml}$ : L-saccharopine $(0.25 \mu \mathrm{mol}) ; \quad \mathrm{L}-\left({ }^{14} \mathrm{C}_{\mathrm{Glu}}\right)$ saccharopine $(0.1$ $\mu \mathrm{Ci}) ; \mathrm{NAD}^{+}(0.5 \mu \mathrm{mol})$; Tris-HCl buffer, $\mathrm{pH} 8.8$ (20.0 $\mu \mathrm{mol})$, and enzyme preparation (150 $\mu \mathrm{g}$ protein). Incubation was for $90 \mathrm{~min}$ at $30^{\circ}$. The reaction was terminated by the addition of sulfosalicylic acid $(25 \mathrm{mg})$ and the precipitated protein removed by centrifugation. To the supernatant glutamate $(1.0 \mu \mathrm{mol})$ was added as carrier. The medium was desalted and the $\left({ }^{14} \mathrm{C}_{5}\right)$ glutamate formed from $\mathrm{L}-\left[{ }^{14} \mathrm{C}_{\mathrm{Glu}}\right]$ saccharopine was separated by high voltage electrophoresis. The radioactivity was determined by liquid scintillation.

Saccharopine oxidoreductase. The incubation medium contained, in $0.1 \mathrm{ml}$ : $\mathrm{L}$-saccharopine $(0.25 \mu \mathrm{mol})$; 
$\mathrm{L}-\left(\mathrm{U}^{14} \mathrm{C}_{\mathrm{Lys}}\right)$ saccharopine $(0.5 \mu \mathrm{Ci}) ; \mathrm{NADP}+(0.5 \mu \mathrm{mol})$; $\mathrm{NH}_{4} \mathrm{Cl}(4.0 \mu \mathrm{mol})$; Tris-HCl buffer, $\mathrm{pH} 9.2(25.0 \mu \mathrm{mol})$, and enzyme preparation $(250 \mu \mathrm{g}$ protein). Incubation was for $1 \mathrm{hr}$ at $30^{\circ}$. The reaction was terminated by the addition of sulfosalicylic acid (25 mg). L-Lysine (1.0 $\mu \mathrm{mol})$ was added as a carrier [8]. The procedures of amino acid analysis of the deproteinized incubation medium were the same as those described above.

Liquid scintillation. The amino acid spots were cut out from paper and shaken in $2 \mathrm{mI} 50 \%$ methanol solution at room temperature for $4 \mathrm{hr}$. Then $15 \mathrm{ml}$ of Bray's scintillation solution (2,5-diphenyloxazole, $4 \mathrm{~g}$; 1, 4-bis[2-(5-phenyloxazolyl)]benzene, $0.2 \mathrm{~g}$; naphthalene, $60 \mathrm{~g}$; methanol, $100 \mathrm{ml}$; ethylene glycol, $20 \mathrm{ml}$; and 1,4-dioxane to I liter) were added to the extract and counted in a Packard Tri-Carb liquid scintillation counter [36] after 4 hr equilibrium in the counting chamber.

Quench correction was made by using an automatic external standard [2].

\section{Results}

\section{Saccharopine Dehydrogenase}

The skin fibroblasts grown in tissue culture media from six healthy control subjects established the presence of saccharopine dehydrogenase (Table I). The fibroblast mitochondrial preparations showed an activity 6 times that of the whole cell homogenate, which indicated that saccharopine dehydrogenase is a mitochondrial enzyme. Saccharopine dehydrogenase activity was absent in the skin fibroblasts grown from the patient with saccharopinuria.

\section{Lysine-oxoglutarate Reductase}

Lysine-oxoglutarate reductase activity has been previously demonstrated in cultured skin fibroblasts [5]. The present investigation of the enzyme activity in skin fibroblasts from mitochondrial preparations from healthy individuals showed an activity 5 times greater

Table I. Saccharopine dehydrogenase activity in skin fibroblasts

\begin{tabular}{lcc}
\hline \multicolumn{1}{c}{ Subject } & $\begin{array}{c}\text { Whole cell homogenate, } \\
\text { units }^{1}\end{array}$ & Mitochondria, units \\
& & \\
Control subjects & & \\
Range & $177-320$ & $980-2,410$ \\
Mean & 233 & 1,466 \\
Patient & 0 & 0
\end{tabular}

1 One unit is defined as 1 pmol glutamate formed $/ \mathrm{min} / \mathrm{mg}$ protein.

2 Six healthy individuals aged $2-40$ years.
Table II. Lysine-oxoglutarate reductase activity in skin fibroblasts

\begin{tabular}{lcc}
\hline \multicolumn{1}{c}{ Subject } & $\begin{array}{c}\text { Whole cell homogenate, } \\
\text { units }\end{array}$ & Mitochondria, units ${ }^{1}$ \\
\hline Controls & \\
Range & & \\
Mean & $550-1,570$ & $2,730-8,230$ \\
Patient & 900 & 4,400 \\
Hyperlysinemia & 333 & 1,170 \\
Patient $A J$ & & \\
Patient $J J$ & 37 & \\
Patient $P J$ & 35 & \\
\hline
\end{tabular}

${ }^{1}$ One unit is defined as 1 pmol saccharopine formed $/ \mathrm{min} / \mathrm{mg}$ protein.

2 Six healthy individuals aged $2-40$ years.

3 Values recalculated from Dancis et al. [5].

than that of the whole cell homogenate, which suggested that lysine-oxoglutarate reductase is also a mitochondrial enzyme. Similar results have been reported in rat liver $[14,15]$. Subcellular fractionation has therefore proved to be a valuable primary purification procedure in the present studies. The activity of lysineoxoglutarate reductase in the skin fibroblasts grown from the patient with saccharopinuria was $37 \%$ of that in normal control subjects (Table II).

\section{Saccharopine Oxidoreductase}

Enzyme activity in cultured skin fibroblasts was absent in healthy control subjects. In the patient with saccharopinuria, the respective enzyme activities in the whole cell homogenate and in the mitochondria of the cultured fibroblasts were 63 and $85 \mathrm{pmol}$ lysine formed $/ \mathrm{min} / \mathrm{mg}$ protein.

\section{Discussion}

Enzyme studies conducted on skin fibroblasts from a patient with saccharopinuria have revealed the complete absence of saccharopine dehydrogenase compared with healthy control subjects. It would appear that the basic defect lies between saccharopine and $\alpha$-aminoadipate- $\delta$-semialdehyde in the lysine degradative pathway (Fig. 1). Subsequently, saccharopine and other lysine metabolites accumulate in the body fluid and are excreted in the urine.

In the Finnish patient with saccharopinuria described [23], a $60 \%$ reduction in the activity of saccharopine dehydrogenase was reported in cultured skin fibroblasts and in muscle tissue; in our experience the estimation of saccharopine dehydrogenase activity by 


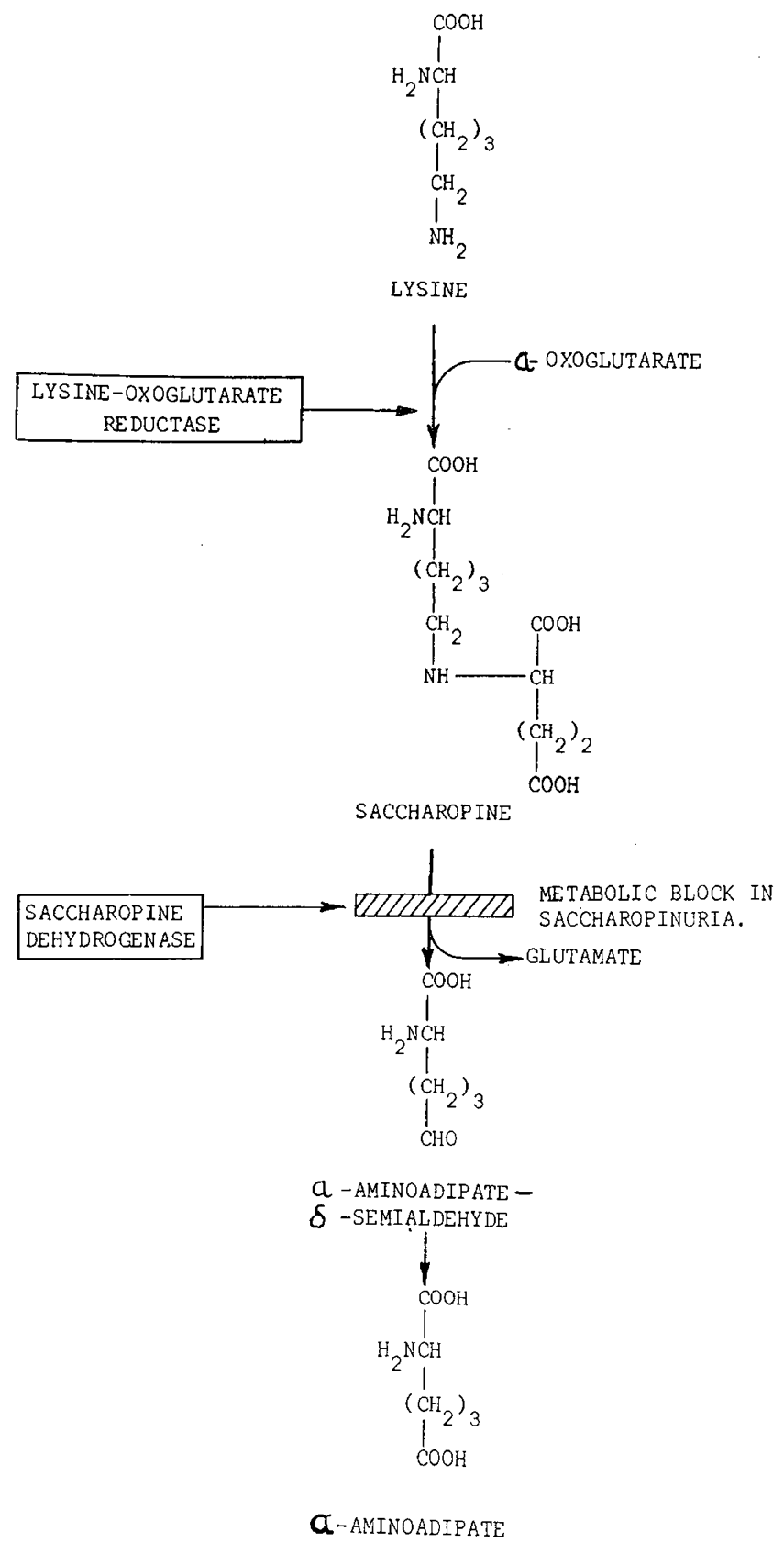

Fig. 1. The major degradative pathway of lysine in mammals.

the measurement of $\alpha$-aminoadipate- $\delta$-semialdehyde proved to be unreliable in the present study and may account for the higher activity of saccharopine dehydrogenase reported by the Finnish group. Alternatively, the Finnish patient and our patient may reflect two different metabolic disorders.

In Table III are compared the plasma levels of saccharopine, citrulline, and lysine in the two patients with saccharopinuria, in three patients with hyper- lysinemia (lysine-oxoglutarate reductase deficiency) and healthy control subjects. It can be seen that the level of plasma lysine in the Finnish patient is twice that of our patient with saccharopinuria and that both

Table III. Levels of lysine, saccharopine, and citrulline in plasma of two patients with saccharopinuria, three patients with hyperlysinemia (lysine-oxoglutarate reductase deficiency), and in healthy control subjects $(\mu \mathrm{M})$

\begin{tabular}{cccc}
\hline Patient source & Lysine & Saccharopine & Citrulline \\
\hline Saccharopinuria & & & \\
Carson et al. $[3]$ & 607 & 24 & 101 \\
Simell et al. $[24]$ & 1,320 & Trace & 15 \\
Hyperlysinemia & & & \\
Woody et al. $[28]$ & $1,164-1,541$ & N.R.1 & N.R.1 \\
Woody et al. $[28]$ & $685-1,027$ & & 1. \\
$\quad$ Woody et al. $[28]$ & $917-1,095$ & & \\
Healthy control subjects & & & \\
$\quad$ Scriver and Davies & $71-151$ & 0 & $12-30$ \\
$\quad[22]$ & & & \\
\hline
\end{tabular}

${ }^{1}$ N.R. : not recorded.

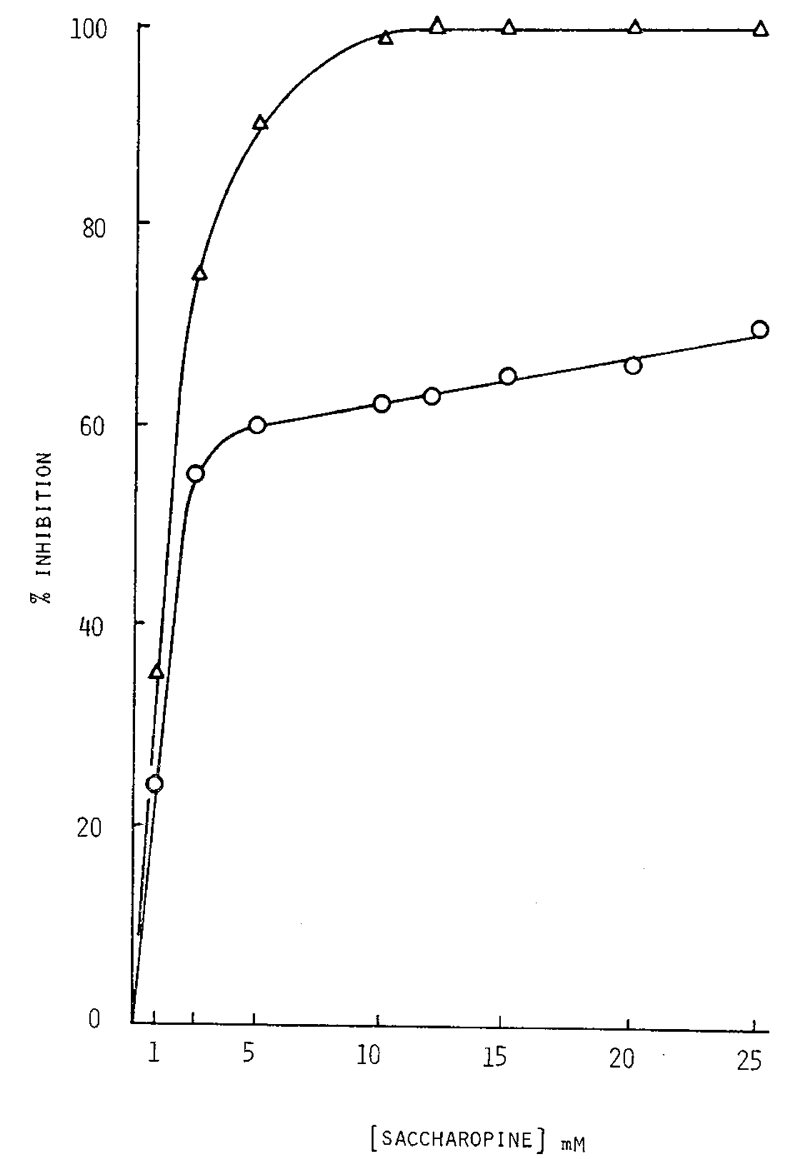

Fig. 2. Inhibitory effect of saccharopine on lysine-oxoglutarate reductase of human skin fibroblasts. $\triangle$ : normal control subjects; $O$ : patient with saccharopinuria. 
patients have levels of lysine comparable with reported levels for a patient with hyperlysinemia.

The high level of lysine in saccharopinuria may result from an alteration in lysine-oxoglutarate reductase activity. The results obtained from the skin fibroblasts both of the normal subjects and our patient with saccharopinuria (Table II) shows that the rate of saccharopine synthesis in the patient is considerably reduced compared with the normal control subjects. In three patients reported [5] with hyperlysinemia due to lysine-oxoglutarate reductase deficiency, saccharopine synthesis was approximately $10 \%$ of that in the patient with saccharopinuria and $3.5 \%$ of that in normal control subjects. However, lysine load tests in our patient with saccharopinuria [3] did not suggest a primary defect in the first step of lysine degradation, inasmuch as an appreciable increase in saccharopine synthesis occurred.

Alternatively, the hyperlysinemia may have resulted from an inhibition of lysine-oxoglutarate reductase secondary to the presence of the high levels of saccharopine in the tissues of the patient. This possibility in both liver and fibroblasts was indicated by the decrease in lysine-oxoglutarate reductase activity observed in incubations in which exogenous saccharopine was included. It was demonstrated in skin fibroblasts that the enzyme activity could be significantly inhibited by saccharopine at concentrations greater than $1 \mathrm{~mm}$
(Fig. 2). An examination of the plasma of the patient showed that the concentration of saccharopine in her blood was $24.5 \mu \mathrm{M}$. In comparison with the concentration of exogenous saccharopine included in the in vitro studies, this in vivo concentration of $24.5 \mu \mathrm{M}$ is much lower and may not have great inhibitory effect on the enzyme activity. However, the level of saccharopine in plasma does not necessarily reflect the mitochondrial level, which could prove theoretically much greater than that of plasma.

If saccharopine synthesis from lysine were a reversible process, this would account for the increased levels of lysine. An enzyme capable of hydrolyzing saccharopine to lysine and $\alpha$-oxoglutarate has been reported [27]. This enzyme, saccharopine oxidoreductase, has been found to be present in the livers of various mammals studied. The highest enzyme activity was found in the livers of herbivorous animals and the lowest activity in carnivorous animals. The variation of the level of lysine synthesis in these mammals may be interpreted to suggest that saccharopine oxidoreductase activity is correlated with the protein content of the diet of the animals. The results from current studies have shown that its activity is absent from the skin fibroblasts cultured from six normal subjects. In contrast, it has been found that the skin fibroblasts grown from the patient with saccharopinuria exhibit a definite enzyme activity. This finding suggests that, in

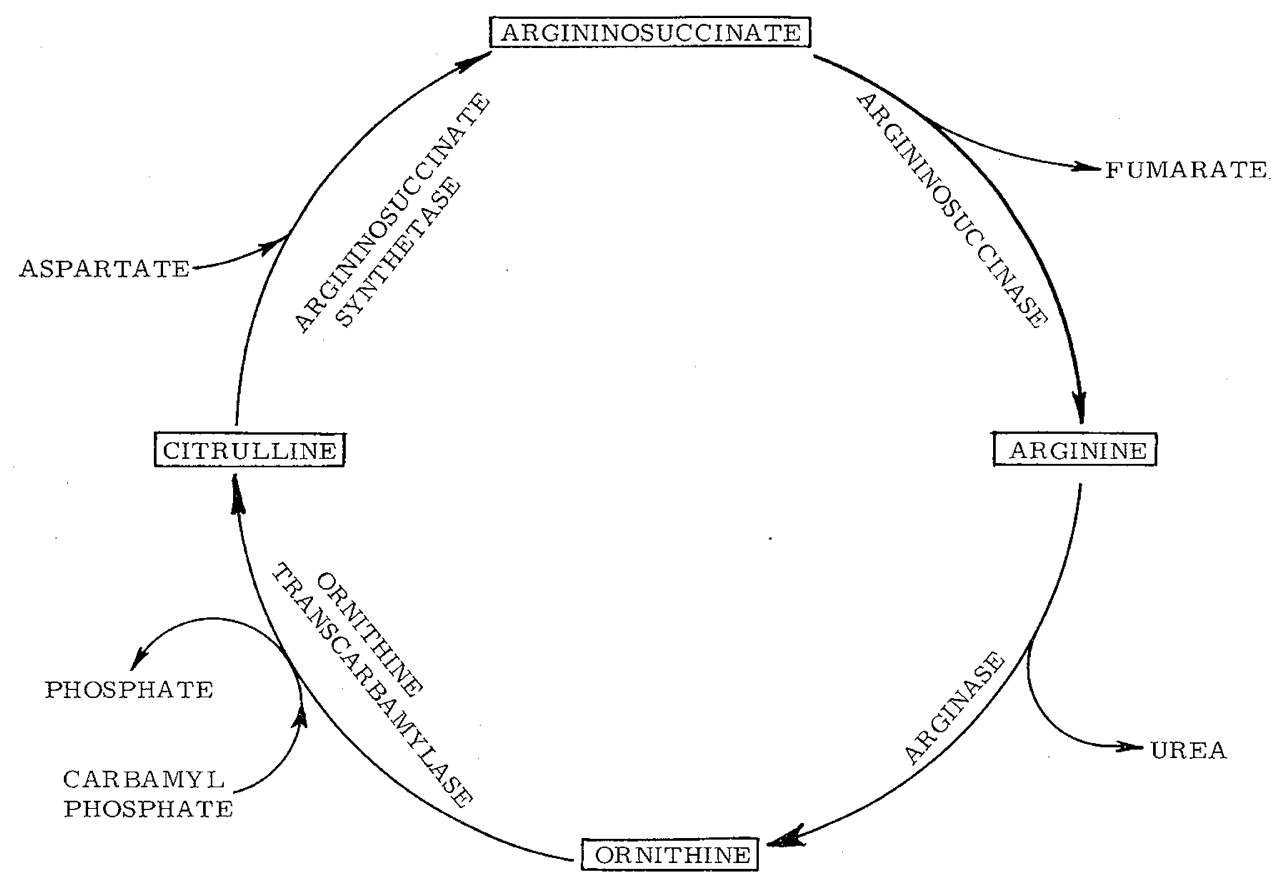

Fig. 3. Enzymes of the urea cycle. 
vivo, saccharopine oxidoreductase activity in our patient may be greatly induced in order to metabolize the excess saccharopine present in her body fluid. Activity of enzyme in liver was not determined, as permission for liver biopsy was not obtained.

Identification, characterization, and assay of levels of activity of saccharopine oxidoreductase in liver have been published $[9,10]$.

In our patient the level of citrulline in plasma was about 5 times and in urine 31 times the normal value. This contrasts with normal levels in the Finnish patient. The increased level of citrulline in our patient may reflect a second metabolic disorder which involves the metabolism of citrulline. However, in a preliminary investigation of this disorder, the results of ammonia and citrulline load in blood studies did not suggest a primary defect in the urea cycle of the patient [3] (Fig. 3). An alternative possibility is that citrulline metabolism may be affected secondarily to the primary enzyme defect in saccharopine degradation. Further studies are continuing in an attempt to elucidate the metabolic relationship between saccharopine and citrulline.

The pipecolic acid pathway has been shown to be utilized to a minor degree in the degradative pathway of lysine metabolism in man [11, 29]. Enzyme studies in our patient with saccharopinuria and in patients with hyperlysinemia [5] confirm that the initial steps in lysine degradation is transamination of the $\epsilon$-amino group with the intermediate formation of saccharopine. The metabolic block in the patient with saccharopinuria would appear to be due to the absence of saccharopine dehydrogenase which is responsible for the second step in lysine degradation which results in accumulation of saccharopine.

\section{Summary}

Enzyme studies conducted on skin fibroblasts using radioisotope techniques are presented in a patient with saccharopinuria and in healthy control subjects. The results are compared with those of a further patient reported with saccharopinuria and patients with familial hyperlysinemia described in the literature.

\section{References and Notes}

I. Armstrong, M. D., Robinow, M., AND Andrews, I. M.: A case of hyperlysinemia: Biochemical and clinical observations. Pediatrics, 39: 546 (1967).

2. BELL, T. K.: Liquid scintillation counting using external standards and channels ratio techniques for quench correction. Lab. Pract., 17: 809 (1968).

3. Carson, N. A. J.: Saccharopinuria: A new inborn error of 1 - sine metabolism. In: J. D. Allan, K. S. Holt, J. T. Ireland, and R. J. Pollitt: Proceedings of the Sixth Symposium of the Society for the Study of Inborn Errors of Metabolism, Zurich, p. 163 (Livingstone, Edinburgh, 1969).

4. Carson, N. A. J., Scally, B. G., Neill, D. W., and Carré, I. J.: Saccharopinuria: A new inborn error of lysine metabolism. Nature, 218: 679 (1968).

5. Dancrs, J., Hutzler, J., Cox, R. P., And Woody, N. C.: Familial hyperlysinemia with lysine-oxoglutarate reductase insufficiency. J. Clin. Invest., 48 : 1447 (1969).

6. Darling, S., and Larsen, P. O.: Saccharopine, a new amino acid in baker's and brewer's yeast. I. Isolation and properties. Acta. Chem. Scand., 15: 743 (1961).

7. Edwards, J. H.: Painless skin biopsy. Lancet, $i: 496$ (1960).

8. Fellows, F. C. I.: Studies of lysine metabolism with particular reference to saccharopinuria. Ph.D. thesis, The Queen's University of Belfast, 1972.

9. Fellows, F. C. I.: Biosynthesis and degradation of saccharopine, an intermediate of lysine metabolism. Biochem. J., 136: 321 (1973).

10. Fellows, F. C. I., AND Lewis, M. H. R.: Lysine metabolism in mammals. Biochem. J., 136: 329 (1973).

11. Gatfield, P. D., Taller, E., Hinton, G. G., Wallace, A. G., Abdelnour, G. M., And Haust, M. D.: Hyperpipecolatemia: A new metabolic disorder associated with neuropathy and hepatomegaly. Can. Med. Ass. J., 99: 1215 (1968).

12. Ghadimi, H., Binnington, V. Y., and Pecora, P. J.: Hyperlysinemia associated with retardation. New Engl. J. Med., 273: 723 (1965).

13. Grove, A. J., and Henderson, L. M.: The metabolism of $\mathrm{p}$ and L-lysine in the intact rat, perfused liver and liver mitochondria. Biochim. Biophys. Acta, 165: 113 (1968).

14. Higashino, K., Fujroka, M., Aoki, T., and Yamamura, Y.: Metabolism of lysine in rat liver. Biochem. Biophys. Res. Commun., 29: 95 (1967).

15. Higashino, K., Tsukada, K., and Lieberman, I.: Saccharopine, a product of lysine breakdown by mammalian liver. Biochem. Biophys. Res. Commun., 20: 285 (1965).

16. Hutzler, J., AND Dancis, J.: Conversion of lysine to saccharopine by human tissues. Biochim. Biophys. Acta, 158: 62 (1968).

17. Hutzler, J., and Dancis, J.: Saccharopine cleavage by a dehydrogenase of human liver. Biochim. Biophys. Acta, 206: 205 (1970).

18. KUo, M. H., SAunders, P. P., ANd Broquist, H. P.: A metabolite of $\alpha$-aminoadipic acid in yeast: Relation to lysine biosynthesis. Biochem. Biophys. Res. Commun., S: 227 (1962).

19. Kuo, M. H., Saunders, P. P., And Broquist, H. P.: Lysine biosynthesis in yeast: A new metabolite of $\alpha$-aminoadipic acid. J. Biol. Chem., 239: 508 (1964).

20. Lowry, D. H., Rosebrough, N. J., FarR, A. L., and Randall, R. J.: Protein measurement with the Folin phenol reagent. J. Biol. Chem., 193: 265 (195I).

21. Rothstein, M., and Miller, L. L.: The conversion of lysine to pipecolic acid in the rat. J. Biol. Chem., 211:851 (1954).

22. SCRIVER, C. R., ANd Davies, E.: Endogenous renal clearance rates of free amino acids in pre-pubertal children. Pediatrics, 36: $592(1965)$.

23. Simell, O., Johansson, T., and Aula, P.: Enzyme defect in saccharopinuria. J. Pediat., 82: 54 (1973). 
24. Simell, O., Visakorpi, J. K., ANd Donner, M.: Saccharopinuria. Arch. Dis. Childhood, 47: 52 (1972).

25. SMITH, I. (ED.): Chromatographic and electrophoretic techniques, Ed. 3 (Pitman Press, Bath, England, 1969).

26. WANG, F. C. I., ANd CARSon, N. A. J.: Saccharopinuria: A new inborn error of lysine metabolism, identification and isolation of lysine metabolites. In: Sixth Colloquium in Amino Acid Analysis. Technicon Monograph no. 3, p. 118 (Technicon Corporation, Tarrytown, N. Y., 1968).

27. WANG, F. C. I., AND LEWIS, M. H. R.: Lysine biosynthesis in mammals. Biochem. J., 130: 74p (1972).

28. Woody, N. C., Hutzler, J., AND DANCIS, J.: Further studies of hyperlysinemia. Amer. J. Dis. Child., 112: 577 (1966).

29. Woody, N. C., ANd Pupene, M. B.: Derivation of pipecolic acid from L-lysine by familial hyperlysinemics. Pediat. Res., 5: $511(1971)$.

30. Amersham, Bucks, UK.

31. Technicon Corporation, Tarrytown, N. Y.
32. Baird \& Tatlock, Chadwell Heath, Essex, England.

33. Shandon Scientific Co., Inc., Sewickley, Penn.

34. Flow Labs, Inc., Rockville, Md.

35. MSE, Inc., Cleveland, Ohio.

36. Packard Instrument Co., Downer's Grove, Ill.

37. We wish to thank Professor I. J. Carré, Department of Child Health, The Queen's University of Belfast, for his help and encouragement and Mr. Alan Bittles for his advice and help with tissue cultures. We are indebted to Professor Elmore, Department of Biochemistry, for the use of specialized equipment in his department.

38. Dr. F. C. I. Fellows was known before 1973 as Dr. F. C. I. Wang.

39. Requests for reprints should be addressed to: NinA A. J. Carson, M.D., Research Laboratory, Department of Child Health, Institute of Clinical Science, Grosvenor Rd., Belfast, BT126BJ, Northern Ireland.

40. Accepted for publication September 12, 1973. 